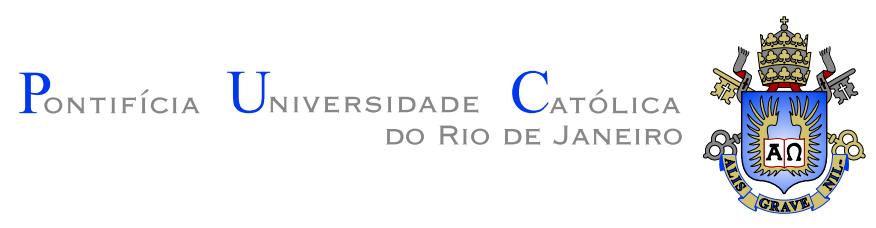

João Pedro Bumachar Resende

\title{
Pré-Pagamento, Default e Securitização Financeira: Um Modelo de Equilíbrio Geral
}

Dissertação de Mestrado

Dissertação apresentada como requisito parcial para obtenção do grau de Mestre pelo Programa de Pós-graduação em Economia do Departamento de Economia da PUC-Rio

Orientador: Prof. Juan Pablo Torres-Martínez

Rio de Janeiro

Fevereiro de 2006 


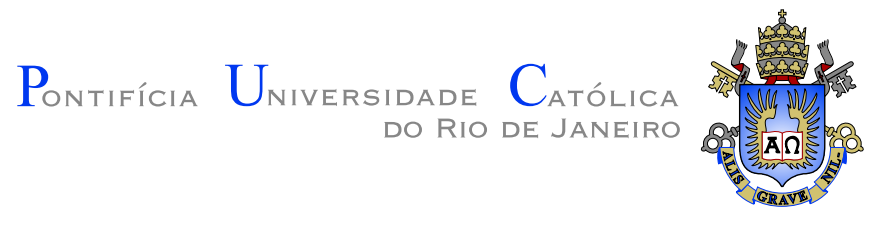

João Pedro Bumachar Resende

\title{
Pré-Pagamento, Default e Securitização Financeira: Um Modelo de Equilíbrio Geral
}

Dissertação apresentada como requisito parcial para obtenção do grau de Mestre pelo Programa de Pós-graduação em Economia do Departamento de Economia do Centro de Ciências Sociais da PUC-Rio. Aprovada pela Comissão Examinadora abaixo assinada.

\author{
Prof. Juan Pablo Torres-Martínez \\ Orientador \\ Departamento de Economia - PUC-Rio
}

Prof. Filipe Martins-da-Rocha

Université Paris IX

Prof. Carlos Hérves

Universidad de Vigo

Prof. João Pontes Nogueira

Coordenador Setorial do Centro de Ciências Sociais - PUC-Rio

Rio de Janeiro, 10 de Fevereiro de 2006 
Todos os direitos reservados. É proibida a reprodução total ou parcial do trabalho sem autorização da universidade, do autor e do orientador.

\section{João Pedro Bumachar Resende}

Graduou-se em Administração de Empresas na Fundação Getúlio Vargas - São Paulo.

Ficha Catalográfica

Resende, João Pedro Bumachar

Pré-Pagamento, Default e Securitização Financeira: Um Modelo de Equilíbrio Geral / João Pedro Bumachar Resende; orientador: Juan Pablo Torres-Martínez. - Rio de Janeiro : PUC-Rio, Departamento de Economia, 2006.

v., 34 f: il. ; $29,7 \mathrm{~cm}$

1. Dissertação (mestrado) - Pontifícia Universidade Católica do Rio de Janeiro, Departamento de Economia.

Inclui referências bibliográficas.

1. Economia - Tese. 2. Pré-Pagamento. 3. Default. 4. Equilíbrio Geral. 5. Securitização. I. Torres-Martínez, Juan Pablo. II. Pontifícia Universidade Católica do Rio de Janeiro. Departamento de Economia. III. Título. 


\section{Agradecimentos}

Àqueles que até aqui me acompanharam e àqueles que de cá me acompanharão. 


\section{Resumo}

Resende, João Pedro Bumachar; Torres-Martínez, Juan Pablo. PréPagamento, Default e Securitização Financeira: Um Modelo de Equilíbrio Geral. Rio de Janeiro, 2006. 34p. Dissertação de Mestrado - Departamento de Economia, Pontifícia Universidade Católica do Rio de Janeiro.

A securitização desenvolvida no modelo de Steinert e Torres-Martínez(2005) é similar em muitos aspectos àquela encontrada no mercado de MortgageBacked Securities(MBS). Afinal, uma MBS é um título cujos fluxos de caixa são gerados por contratos de dívida garantidos por um imóvel. Porém, MBS estão sujeitas não só a risco de default, mas também a risco de prépagamento, já que qualquer um dos contratos de dívida que as lastreiam pode ser sempre pago, parcialmente ou integralmente, antes do vencimento pelo seu valor de face. Nesse trabalho construímos um modelo de equilíbrio geral com securitização e risco de default e pré-pagamento, tratando, assim, uma economia mais próxima ao mercado de MBS.

\section{Palavras-chave}

Pré-Pagamento. Default. Equilíbrio Geral. Securitização. 


\section{Abstract}

Resende, João Pedro Bumachar; Torres-Martínez, Juan Pablo. Prepayment, Default and Securitization: a General Equilibrium Model . Rio de Janeiro, 2006. 34p. MsC Thesis - Departament of Mathematics, Pontifícia Universidade Católica do Rio de Janeiro.

The securitization developed in Steinert and Torres-Martínez (2005) model is similar in many aspects to that in the market for Mortgage-Backed Securities. After all, a MBS is a bond whose cash flows are generated by debt contracts insured by a property. However, MBS are subjected not only to default but also to prepayment risk, since any debt contract backing it can be paid partially or totally by its face value before retirement. In this work, we set up a general equilibrium model with securitization and both default and prepayment risks. By doing this, we model an economy more realistic when we consider the market for MBS.

\section{Keywords}

Prepayment. Default. General Equilibrium. Securitization. 


\section{Sumário}

1 Introdução $\quad 8$

2 Modelo 11

3 Existência de Equilíbrio 17

4 Observação 18

5 Conclusão $\quad 19$

$\begin{array}{lr}\text { Referências Bibliográficas } & 20\end{array}$

$\begin{array}{ll}\text { Apêndice } & 21\end{array}$

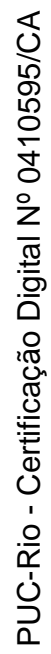

